\title{
Nutritional status characteristics of infants presenting with neonatal cholestasis
}

\author{
Kant Bharti L. ${ }^{1}$, Kishun J. ${ }^{2 *}$ \\ DOI: https://doi.org/10.17511/ijpr.2020.i05.02 \\ 1 Laxmi Kant Bharti, Additional Professor, Department of Pediatric Gastroenterology, Sanjay Gandhi Postgraduate Institute of Medical \\ Sciences(SGPGI), Lucknow, Uttar Pradesh, India. \\ 2* Jai Kishun, Assistant Professor, Department of Biostatistics and Health Informatics, Sanjay Gandhi Postgraduate Institute of Medical \\ Sciences(SGPGI), Lucknow, Uttar Pradesh, India.
}

Background: Neonatal cholestasis (NC) is one of the commonest presentations in early infancy diseases. The nutritional status of infants may be affected by many factors. Impaired bile flow may further lead to the nutritional compromise of infants. Timely nutritional assessment and adequate nutritional support in the form of adequate breastfeeding and if required appropriate formulae feeding according to age and weight is crucial for better outcomes in improving morbidity and decreasing mortality of infants with NC. Methods: Consecutive 143 patients of NC up to 12 months enrolled from the HIS data (hospital information system). Anthropometric examination, mode, and type of feeding and serum markers like LFT (liver function test) and $\mathrm{Hb}$ (hemoglobin) were recorded. Data were analyzed by IAP growth parameters and SPSS 21 . Results: The mean age of NC presentation was 3.6 months. 74(51.7\%) were on mixed feeding, $61(42.6 \%)$ were exclusively breastfed (EBF) and only $8(5.6 \%$ ) infants were on only top feeding by formula feeding or bovine milk feed. $39.16 \%$ were undernourished and around $19.5 \%$ were stunted.40\% infants were anemic. The median value of serum albumin in top-fed and EBF (exclusive breastfed) was low. Conclusions: Malnutrition is common in infants with NC. There area different feeding pattern and type observed in infants with NC. EHBA (extrahepatic biliary atresia) is the most common diagnosis in infants with NC presented to the tertiary care center. Early nutritional assessment and timely nutritional supplementation having a crucial role in the outcome of patients with various diagnoses in NC.

Keywords: Neonatal cholestasis, Undernutrition, Breastfeeding, Nutritional status, Infant

Corresponding Author

Jai Kishun, Assistant Professor, Department of Biostatistics and Health Informatics, Sanjay Gandhi Postgraduate Institute of Medical Sciences(SGPGI), Lucknow, Uttar Pradesh, India.

Email: Ikbharti@yahoo.com
How to Cite this Article

To Browse

Bharti LK, Kishun J. Nutritional status characteristics of infants presenting with neonatal cholestasis. Pediatric Rev Int J Pediatr Res. 2020;7(5):199-203. Available From https://pediatrics.medresearch.in/index.php/ijpr/arti cle/view/599

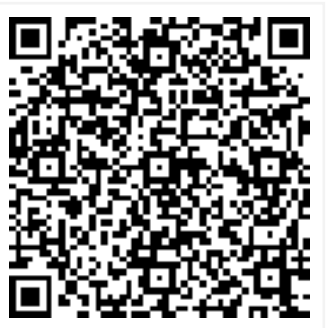

Manuscript Received 2020-05-26

Conflict of Interest No
Review Round 1 2020-06-05

Funding Nil

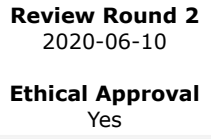

Review Round 3

Plagiarism X-checker $8 \%$
Accepted 2020-06-15

Note

(c) 2020 by Laxmi Kant Bharti, Jai Kishun and Published by Siddharth Health Research and Social Welfare Society. This is an Open Access article licensed under a Creative Commons Attribution 4.0 International License https://creativecommons.org/licenses/by/4.0/ unported [CC BY 4.0]. 


\section{Introduction}

Malnutrition affects nearly two-thirds of children with chronic liver disease [1]. Physiological jaundice in the neonate is a common condition, which rarely extends beyond two weeks of life.When jaundice extends beyond two weeks of life,it's known as pathological jaundice, and the majority of times it is due to neonatal cholestasis (NC).If jaundice persists beyond two weeks in term infant and three weeks in preterm,conjugated and unconjugated both serum bilirubin levels should be done to exclude the diagnosis of NC. Worldwide, NC affects $1 / 2500$ live births, and these figures are steady for almost the last three decades.In our country like India, NC consists of $19 \%-33 \%$ of all chronic liver disease(CLD) in children reaching tertiary care hospital.NC is being more and more recognized in Indiadue to multiple factors.One of the most important campaigns to recognize a case of neonatal cholestasis was "Yellow alert" drive started by former Prof and Head, Dr. S. K. Yachha, Department of Pediatric Gastroenterology,SGPGI,Lucknow, who was also President and Secretary ISPGHAN (Indian Society of Pediatric Gastroenterology, Hepatology, and Nutrition). This yellow alert movement helped very much to pediatricians of Northern India to recognize cases of NC and timely referral to the appropriate center. The consensus statement for the management of NC is published in 2000 in Indian Pediatrics [2]. NC is defined as a condition of increased conjugated bilirubin in newborns because of diminished bile flow. Conjugated hyperbilirubinemia in a neonate is defined as a serum direct/conjugated bilirubin concentration greater than $1.0 \mathrm{mg} / \mathrm{dl}$ if the total serum bilirubin (TSB) is $<5.0 \mathrm{mg} / \mathrm{dl}$ orgreater than 20 percent of TSB if the TSB is $>5.0 \mathrm{mg} / \mathrm{dl}$ [3]. Because of the disease process, especially deficiency of bile in the small intestine, there may be an impact on digestion and absorption of important nutrients. In some of NCS(Neonatal cholestasis syndrome) etiology like alagille syndrome, progressive familial intrahepatic cholestasis (PFIC) and the choledochal cyst may be associated with pancreatic insufficiency, which further aggravates the malabsorption in infants $[4,5]$. Nutritional deficiencies are common in children with NC, particularly when they develop CLD. The present retrospective study was planned with the aim to know:

01. Nutritional status assessment in infants with NC

02. Feeding behaviors of infants with NC

\section{Methods}

This is a retrospective study planned on infants (up to 12 months age) with NC, whois admitted in the Department of Pediatric Gastroenterology, Sanjay Gandhi Postgraduate Institute of Medical Sciences, Lucknow, India. Dietary, anthropometric, and laboratory data of childrenretrieved in NC admitted during the period January 2018 to December 2018.

Inclusion criteria: All infants with NC $\leq 12$ months age.

\section{Exclusion criteria}

- 12 months age

- NC infants having other comorbidities like major congenital heart disease, renal disease, etc.

A total of 163 patients of neonatal and infantile cholestasis were admitted in the study period, of which 20 cases were more than 12 months old,hence excluded from the study.Data of 143 infants (upto12 months)was collected from our hospital information system (HIS). Dietary history, anthropometric data, which included weight (Birth weight and current weight), length, and head circumference were recorded.Modes of feedingwhether exclusively breastfed (EBF), top-fed or mixed (both breastfeed and top feed) were noted.Biochemical parameters were also collected as a marker of nutritional status like- liver functions test(LFT)total protein and albumin, hemoglobin $(\mathrm{Hb})$. Serum bilirubin, SGPT, SGOT was also recorded. Children diagnosed with extrahepatic biliary atresia (EHBA) were transferred to the Department of Pediatric surgery for the portoenterostomy procedure. Ethical requirements not needed as the data are taken from HIS and no personal information of any patient disclosed in this study.

Statistical Analysis: Data initially entered in window 10 excel sheet. BMI was calculated based on IAP growth charts [11]. Data were analyzed using appropriate statistical techniques using SPSS 21.

\section{Results}

A total of 143 patients of NCup to 12 months of age were admitted tothe Department of Pediatric Gastroenterology during the study period. The male to female ratio was $89(62.2 \%): 54(37.8 \%)$. The mean age of presentation was 3.6 months. 
The youngest patient was onemonth and the oldest patient was 12 months.(Figure-1)).

Till the infants were discharged from hospital following were diagnoseddiseases and rest NCS were under evaluation (Table-1).

Table-1: Etiology of Neonatal cholestasis

\begin{tabular}{|l|l|l|}
\hline S.No & \multicolumn{1}{|c|}{ Etiology } & \multicolumn{1}{|c|}{$\%$} \\
\hline 1. & EHBA & $80(56 \%)$ \\
\hline 2. & NCS(under work up) & $29(20 \%)$ \\
\hline 3. & PFIC & $17(12 \%)$ \\
\hline 4. & Metabolic Liver Disease & $10(7 \%)$ \\
\hline 5. & Sepsis & $7(5 \%)$ \\
\hline 6. & Total & $143(100 \%)$ \\
\hline
\end{tabular}

Table-2: Anthropometric measurement of children with Neonatal cholestasis

\begin{tabular}{|l|l|l|l|}
\hline \multirow{2}{*}{ S. No } & \multicolumn{1}{|c|}{ Parameters } & \multicolumn{2}{|c|}{ NCS cases } \\
\cline { 3 - 4 } & & $<3$ rd centile & $>3$ rd centile \\
\hline 1 & Weight & $56(39.16 \%)$ & $87(60.84 \%)$ \\
\hline 2 & Height(length) & $28(19.59 \%)$ & $115(80.41 \%)$ \\
\hline 3 & Head Circumference & $13(9.10 \%)$ & $130(90.90 \%)$ \\
\hline
\end{tabular}

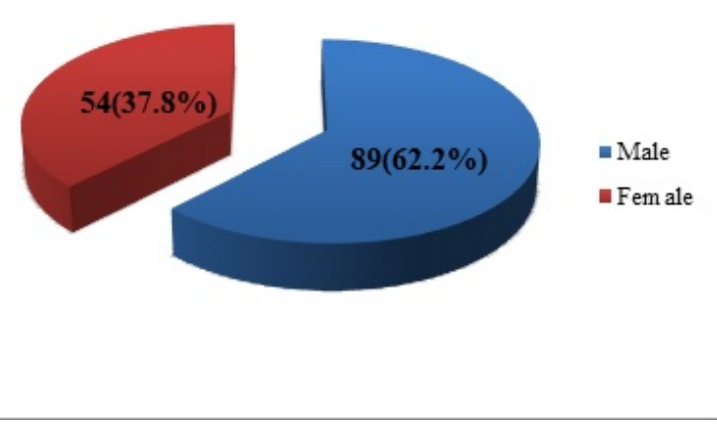

Fig-1: Male to Female ratio.

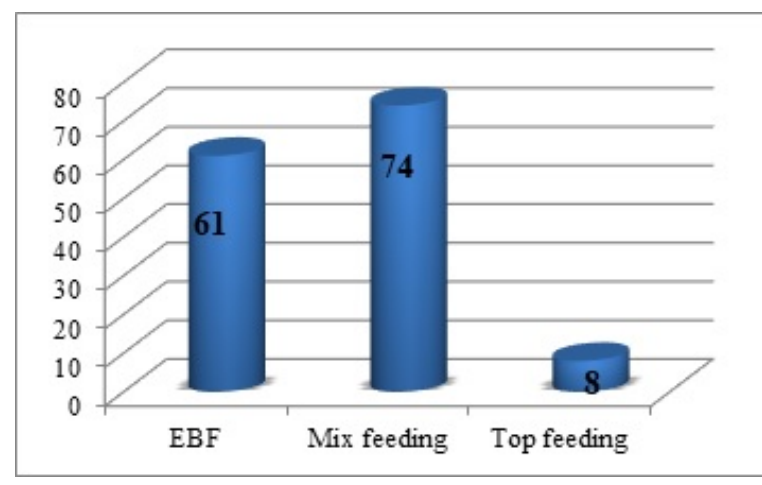

Fig-2: Type of feed.

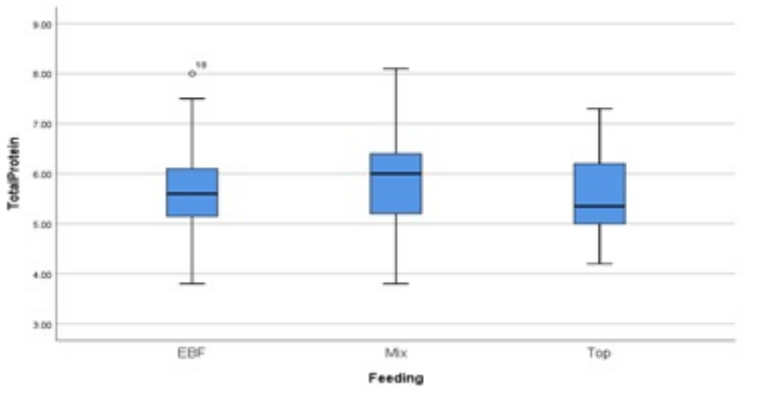

Fig-3: Box plot of total protein and mode of feeding.

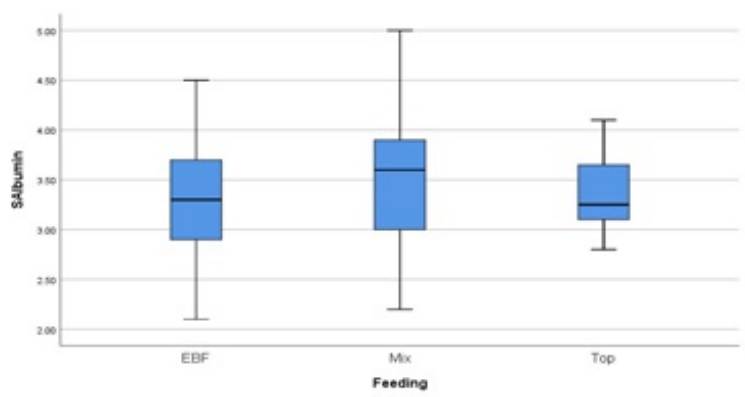

Fig-4: Box plot of serum albumin and mode of feeding.

Regarding the type of feeding analysis, of total 143 NCS infants-74(51.7\%) were on mixed feeding, $61(42.6 \%)$ were exclusively breastfed(EBF) and only $8(5.6 \%)$ infants were on only top feeding by formula feeding or bovine milk feed(Figure$2), 56(39.16 \%)$ children were undernourished and 28(19.59\%)children were stunted and having chronic malnutrition.In $13(9.1 \%)$ children microcephaly was present(Table-2).

Anemia was present in $58(40 \%)$ of infants. The mean total protein(TP) was $5.75 \mathrm{gm} \%$ with a range of 3.8 to $8.1 \mathrm{gm} \%$. The median value of total protein in the EBF group was $5.5 \mathrm{gm} \%$, with a range of 3.8 $\mathrm{gm} \%$ to $7.5 \mathrm{gm} \%$. The median value of total protein in the Mix feeding group was $6.0 \mathrm{gm} \%$, with a range of $3.8 \mathrm{gm} \%$ to $8.1 \mathrm{gm} \%$. The median value of total protein in the top feeding group was $5.3 \mathrm{gm} \%$, with a range of $4.2 \mathrm{gm} \%$ to $7.3 \mathrm{gm} \%$.There was nostatistically significant difference between all three-feeding mode and total protein value(Figure3).

Mean serum albumin value was $3.41 \mathrm{gm} \%$ with a range of 2.1 to $5.0 \mathrm{gm} \%$.Median value of serum albumin in the EBF group was $3.6 \mathrm{gm} \%$, with a range of $2.2 \mathrm{gm} \%$ to $4.5 \mathrm{gm} \%$. The median value of serum albumin in mix feeding group was $3.6 \mathrm{gm} \%$, witha range of $2.3 \mathrm{gm} \%$ to $5.0 \mathrm{gm} \%$. 
The median value of serum albumin in the top feeding group was $3.2 \mathrm{gm} \%$, with a range of 2.8 $\mathrm{gm} \%$ to $4.1 \mathrm{gm} \%$. There was no significant difference between all three-feeding mode and serum albumin value, but the median value of serum albumin in EBF and top feeding group was low(Figure-4).

\section{Discussion}

Nutritional assessment of children with NCS is essential to know the nutritional status to monitor and also for early and appropriate macronutrient and micronutrient supplementation. Undernutrition in NCS may be multifactorial. Apart from the energy requiredforthe growth and development of infants, there is increased energy expenditure due to the disease process. Due to cholestasis, there is further malabsorption contributing to growth failure $[6,7]$. The additional energy requirements may go upto $30 \%$ more for age and weight $[7,8]$. The mean age of presentation in the present study is 3.6 months.

Earlier study done in our department by Yachha SK in 1996, the mean age of presentation was 3.9 months [9]. Early referral is partly due to the yellow alert campaign started by the Department of Pediatric Gastroenterology at SGPGI, Lucknow. The majority $(80 \%)$ of $N C^{\prime}$ s referral to our department is EHBA.EHBA referral has increased in recent times.In 1996 the EHBA referral was $55 \%$ of total NCS patients [9]. This may be due to the fact that EHBA surgery is complicated and requires high expertise. Trained pediatric surgeon in biliary atresia is very less in suburban and rural areas of northern India.

EHBA referral was around $30 \%$ from cumulative data from eight tertiary care centers in India [2]. All these major centers receiving cases of NC having a general paediatrics department, which is lacking in SGPGI. Around half of the total NCS in this study were on breastfeeding and complementary feeding in various forms like the formula and bovine milk. $42.6 \%$ infants were on EBF.This EBF data also correlates with the NFHS-4 [10]. A study was done by Socha $P$ et al [13]from Germanyshow that only $17.64 \%(6 / 34)$ infants were on EBF and the rest $84.36 \%$ (28/34) were on formula feed.

The rate of EBF in German NC infants is much less than in Indian infants with NC. In the present study, more than half of infants were undernourished, and around one-fifth of children were stunted, so they were having chronic malnutrition. A significant proportion of infants ( $40 \%)$ were anemic.
This may be multifactorial due to increased nutritional requirements from the ongoing disease process, apart from malabsorption and maldigestion. Other factors may beorganomegaly and ascites causing early satiety due to gastric compression. The mean total protein value was low only in top-fed children with NC. It shows that infants who were top-fed were inadequately and improperly fed. Mean serum albumin level was low in $E B F$ and top feeding group, and mean serum albumin was normal in the top-fed group. This shows that infants receiving mixed feeding were less nutritionally compromised, as they may be getting additional calories from formula feeds [11]. Islam, et al [12] found that $44.7 \%$ of children were severely underweight; stunting was present in $87.2 \%$. Hasan et al [13] from turkey showed $34.2 \%$ prevalence of acute malnutrition and $39.4 \%$ of chronic malnutrition in infants with NC.There are very few pediatricstudies regarding nutritional status in NC. There is hardly any data from India about the Nutritional status of children with NC. Hence it is important to know the nutritional parameters and feeding behavior of infants with NC. This willfurther determine the nutritional requirement and timely nutritional intervention, which in turn will, reduces the morbidity and mortality of infants. Adequate nutritional support and proper nutritional intervention are crucial for these infants in order to prevent further failure to thrive (FTT) and to improve immunological status to enhance the process of healing and thereby slowing the disease progress.

Limitations of this study- Retrospective study. Follow up not done. So the impact of nutritional intervention done after the nutritional status assessment was not possible, which may have revealed the true impact and outcome of NC.

\section{Conclusion}

This study concludes that NC infants are significantly undernourished.Feeding assessment and requirement is very important. Nutritional intervention should be done periodically and early nutritional intervention should be done to decrease morbidity and mortality.

\section{What does the study add to the existing knowledge?}

This study emphasizesonbreastfeeding even in NC infants, andcalories which are not met with breast 
Feeding, adequate nutritional formula with good MCT (Medium-chain triglyceride) content should be given.

\section{Author's contribution}

Dr. Laxmi Kant Bharti- Manuscript preparation and data collection

Dr. Jai Kishun- Data compilation and statistical analysis

\section{Reference}

01. Bharti LK, Kishun J, Kumar A, Kumar B. Nutritional status assessment in children with chronic liver disease. Gal Int J Health Sci Res. 2020;5(2)84-88.

[Crossref]

02. Consensuses report on neonatal cholestasis syndrome. Pediatric Gastroenterology Subspecialty Chapter of Indian Academy of Pediatrics. Indian Pediatr. 2000;37;845-851. [Crossref]

03. Davis AR, Rosenthal P, Escobar GJ, Newman TB. Interpreting conjugated bilirubin levels in newborns. J Pediatr. 2011;158(4)562-565.

doi: $\quad 10.1016 \% 2 F j . j p e d s .2010 .09 .061 \quad$ [Crossref]

04. Novy MA, Schwarz KB. Nutritional considerations and management of the child with liver disease. Nutrition. 1997;13(3)177-184.

doi: $10.1016 / s 0899-9007(97) 00045-2$ [Crossref]

05. Protheroe SM. Feeding the child with chronic liver disease. Nutrition. 1998;14(10)796-800.

doi: $10.1016 / s 0899-9007(98) 00087-2$ [Crossref]

06. McDiarmid SV, Anand R, Lindblad AS. Principal Investigators and Institutions of the Studies of Pediatric Liver Transplantation (SPLIT) Research Group, Development of a pediatric end-stage liver disease score to predict poor outcome in children awaiting liver transplantation. Transplantation. 2002;74(2)173-181. doi: 10.1097/00007890-200207270-00006 [Crossref]
07. Pierro A, Koletzko B, Carnielli V, Superina RA, Roberts EA, Filler RM, et al. Resting energy expenditure is increased in infants and children with extrahepatic biliary atresia. J Pediatr Surg. $1989 ; 24(6) 534-538$.

doi: $10.1016 / \mathrm{s} 0022-3468(89) 80500-7 \quad$ [Crossref]

08. Kobayashi A, Ohbe Y, Yonekubo A. Fat absorption in patients with surgically repaired biliary atresia. Pediatr Acta. 1983;38(4)307314.

[Crossref]

09. Yachha SK,Kanduri A, Kumar M, Sikora SS, Saxena R, Gupta RK, et al. Neonatal cholestasis syndrome- An appraisal at a tertiary care center. Indian Pediatr. 1996;33(9)729-734. [Crossref]

10. Ogbo FA, Dhami MV, Awosemo AO, Olusanya BO, Olusanya J, Osuagwu UL, et al. Regional Prevalence and Determinants of Exclusive Breastfeeding in India. Int Breastfeed J. $2019 ; 14 ; 20$.

doi: 10.1186/s13006-019-0214-0 [Crossref]

11. Suchy FJ. Neonatal cholestasis. Pediatr Rev. 2004;25(11)388-396.

[Crossref]

12. Islam $S$, Rukunuzzaman $M$, Karim $A B$, Masuduzzaman SM, Alam MJ, Badal MF. Evaluation of Nutritional Status of Hospitalized Infants with Cholestatic Jaundice in a Tertiary Care Center in Bangladesh. Medicine Today. 2020;32(1)10-14.

doi: 10.3329/medtoday.v32i1.44821 [Crossref]

13. Yuksekkaya HA, Cakir M, Tumgor G, Baran $M$, Arikan C, Yagci RV, Aydogdu S. Nutritional status of infants with neonatal cholestasis. Digest Dis Sci. 2008;53(3)803-808. doi: $\quad 10.1007 / s 10620-007-9917-y \quad$ [Crossref]

14. Socha $P$, Koletzko B, Swiatkowska E, Pawlowska J, Stolarczyk A, Socha J. Essential fatty acid metabolism in infants with neonatal cholestasis. Acta Paediatr. 1998;87(3)278-283.

doi: $\quad 10.1080 / 08035259850157327 \quad$ [Crossref] 